\title{
Bosniak classification of renal cystic lesions according to multidetector computed tomography findings*
}

Classificação de Bosniak das lesões císticas renais segundo achados na tomografia computadorizada multidetectores

Christiana Maia Nobre Rocha de Miranda ${ }^{1}$, Carol Pontes de Miranda Maranhão², Carla Jotta Justo dos Santos ${ }^{3}$, Igor Gomes Padilha ${ }^{4}$, Lucas de Pádua Gomes de Farias ${ }^{4}$, Milzi Sarmento da Rocha ${ }^{4}$

Miranda CMNR, Maranhão CPM, Santos CJJ, Padilha IG, Farias LPG, Rocha MS. Bosniak classification of renal cystic lesions according to multidetector computed tomography findings. Radiol Bras. 2014 Mar/Abr;47(2):115-121.

Abstract Renal cystic lesions are usually diagnosed in the radiologists' practice and therefore their characterization is crucial to determine the clinical approach to be adopted and prognosis. The Bosniak classification based on computed tomography findings has allowed for standardization and categorization of lesions in increasing order of malignancy (I, II, IIF, III and IV) in a simple and accurate way. The present iconographic essay developed with multidetector computed tomography images of selected cases from the archives of the authors' institution, is aimed at describing imaging findings that can help in the diagnosis of renal cysts.

Keywords: Bosniak classification; Renal cysts; Multidetector computed tomography.

Resumo As lesões renais císticas são diagnósticos frequentes na prática do médico radiologista, sendo sua caracterização fundamental na determinação da conduta e prognóstico. A classificação de Bosniak permitiu, por meio de tomografia computadorizada, uniformizar e categorizar tais lesões em ordem crescente de malignidade (I, II, IIF, III e IV), sendo esta avaliação realizada de maneira simples e precisa. Este ensaio iconográfico realizado com tomografia computadorizada multidetectores, de casos selecionados dos arquivos do nosso serviço, tem como objetivo demonstrar achados de imagem que possam auxiliar no reconhecimento dos principais aspectos diagnósticos dos cistos renais.

Unitermos: Classificação de Bosniak; Cistos renais; Tomografia computadorizada multidetectores.

\section{INTRODUCTION}

Because of their asymptomatic characteristic and non specificity of their clinical repercussions, renal lesions in general are incidentally diagnosed at images or necropsy ${ }^{(1-3)}$. According to the literature, cystic lesions represent the most common findings in the radiologists' daily practice ${ }^{(2,4)}$ and it is believed that they are acquired lesions, considering that their incidence and prevalence is related to risk factors such as aging, male sex, presence of nephrolithiasis, smoking habit, hypertension and renal dysfunction ${ }^{(5,6)}$.

* Study developed at Clínica de Medicina Nuclear e Radiologia de Maceió (MedRadiUS), Maceió, AL, Brazil.

1. PhD, MD, Titular Member of Colégio Brasileiro de Radiologia e Diagnóstico por Imagem (CBR), Coordinator for the Units of Computed Tomography and Magnetic Resonance Imaging, and Radiologist at the PET-CT Unit of Clínica de Medicina Nuclear e Radiologia de Maceió (MedRadiUS), Teacher of Radiology and Imaging Diagnosis at Universidade Federal de Alagoas (UFAL), Maceió, AL, Brazil.

2. Titular Member of Colégio Brasileiro de Radiologia e Diagnóstico por Imagem (CBR), MD, Radiologist at the Units of Computed Tomography and Magnetic Resonance Imaging of Clínica de Medicina Nuclear e Radiologia de Maceió (MedRadiUS), Maceió, AL, Brazil.

3. MD, Radiologist at the Units of Computed Tomography, Magnetic Resonance Imaging and PET-CT of Clínica de Medicina Nuclear e Radiologia de Maceió (MedRadiUS), Maceió, AL, Brazil.

4. Graduate Students (6th year), School of Medicine - Universidade Federal de Alagoas (UFAL), Maceió, AL, Brazil.

Mailing Address: Dra. Christiana Maia Nobre Rocha de Miranda. Rua Hugo Corrêa Paes, 104, Farol. Maceió, AL, Brazil, 57050-730. E-mail: maiachristiana@globo.com.

Received March 21, 2013. Accepted after revision August 12, 2013.
Renal cysts can be easily identified by means of diagnostic imaging methods and in many cases it is not necessary to resource to histopathological analysis ${ }^{(4)}$. However, complex renal cysts or those with solid components may be found, requiring a more detailed characterization to allow the determination of differential diagnoses and, consequently, of the corresponding therapeutic approach and prognostic evaluation $^{(1,7-9)}$.

Because of such a necessity, Bosniak, in $1986^{(4)}$, developed a classification system based on computed tomography (CT) imaging criteria allowing for the analysis of renal cysts' contour and contents, presence of septations and/or calcifications, and enhancement after contrast agent injection.

By means of such a classification system, renal lesions can be categorized in increasing order of malignancy ${ }^{(1,4,9)}$, as follows: simple (I); minimally complicated (II); minimally complicated requiring follow-up (IIF); indeterminate (III); or cystic neoplasm (IV).

The present pictorial essay is aimed at demonstrating, by means of multidetector computed tomography (MDCT), the main imaging findings of renal cysts, according to the Bosniak classification.

\section{CATEGORY I}

Simple renal cysts represent the greatest majority of renal lesions detected by imaging methods. Such lesions are 
characterized by their homogeneous content with fluid attenuation $(0-20 \mathrm{UH})$, regular contour and a clear interface between the latter the renal parenchyma. Neither septations, nor calcifications, nor enhancement are observed after intravenous contrast agent injection $^{(8,9)}$ (Figure 1). They are easily identifiable by means of ultrasonography (US) where they are characterized as thin walled lesions with anechoic contents ${ }^{(10)}$.

As such lesions are characterized by an appropriate technique, they are always benign with no chance of malignancy, and do not require further investigation ${ }^{(8-10)}$.

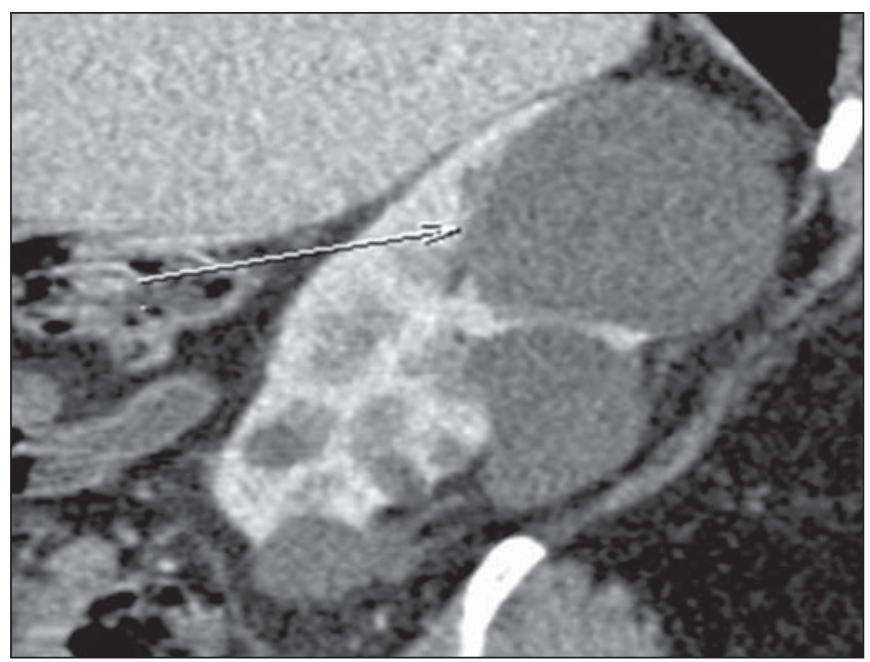

Figure 1. Bosniak category I. MDCT image, sagittal reconstruction demonstrating the presence of homogeneous cystic lesions with fluid attenuation, without calcifications, septations or enhancement after intravenous contrast injection. Simple cyst. Note the presence of a major lesion (arrow) located in the superior renal pole.

\section{CATEGORY II}

Like those classified as category I, cystic lesions classified as category II are also considered benign, but with a minimally complicated appearance. Such lesions may present with thin septations, thickness $<1 \mathrm{~mm}$ (Figure 2), besides small (1-2 mm), linear, parietal or septal calcifications ${ }^{(9-15)}$.

Also in this category, hyperattenuating cysts are observed (attenuation coefficient $>20 \mathrm{UH}$ ), being initially described as cysts with higher attenuation coefficient than the renal parenchyma (typically 40-90 UH) in the absence of contrast injection, and with no contrast enhancement as contrast agent is administered $^{(1,4,9,16)}$. A hyperdense cyst is categorized as II IF its diameter is $<3 \mathrm{~cm}$, and partially exophytic, allowing a better evaluation of the wall thickness $^{(9,14)}$ (Figure 3).

In spite of being considered benign lesions ${ }^{(10,12)}$, there are reports in the literature about rare renal lesions classified into category II, and identified as malignant and potentially malignant according anatomopathological analysis. In such cases, it is possible that the lesions' characteristics have not been completely described, impairing an appropriate classification of the lesions. Also, other extremely rare cases of renal cell carcinomas on the walls of benign cysts are included in this context ${ }^{(9,17-20)}$.

Thus, the differentiation of more complex lesions from those classified as (non surgical) category II makes the diagnosis more difficult, with greater interobserver variation, although it is extremely important since the prognosis and therapeutic approach to be adopted are different in such $\operatorname{cases}^{(1,10,11,14,21)}$.

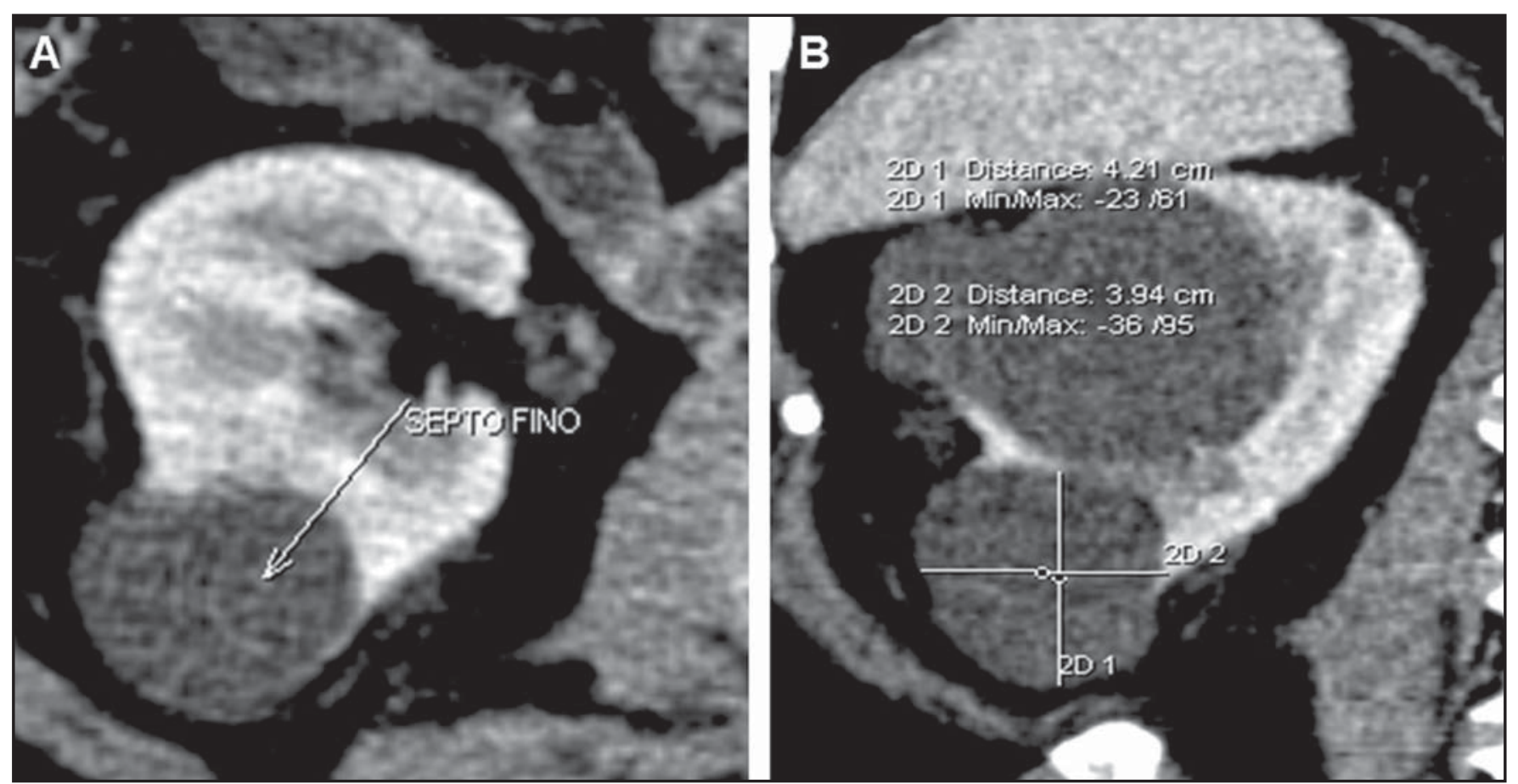

Figure 2. Bosniak category II. MDCT images, axial (A) and coronal (B) reconstructions demonstrating the presence of a cystic lesion with thin septation inside (arrow on A). Minimally complicated cyst. 


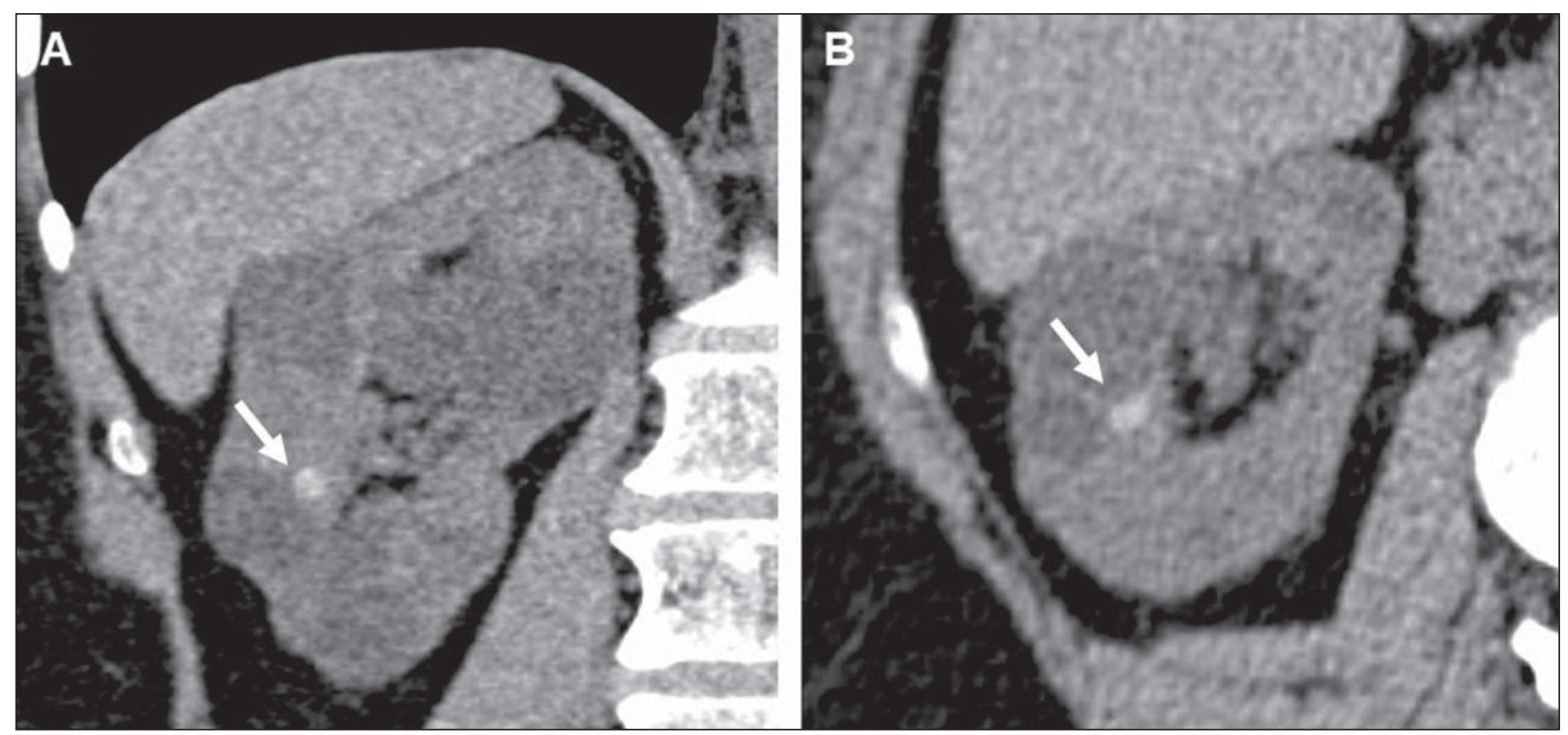

Figure 3. Bosniak category II. MDCT images, coronal (A) and axial (B) reconstructions identifying a round-shaped, hyperattenuating lesion (64 UH density) measuring about $1.0 \mathrm{~cm}$, possibly corresponding to a hemorrhagic cyst or to a cyst with high protein content (arrows). Minimally complicated cyst. Also, note the presence of simple cysts. Bosniak category I.

\section{CATEGORY IIF}

In 1993, Bosniak reviewed his original classification to include category $\operatorname{IIF}^{(8,21,22)}$ for a group of minimally complicated cysts which do not fulfill the characteristics required to be included in category III, but are more complex than those included in category II. Their differentiation is subjective and difficult, with great interobserver variability, but it is essential, considering the different therapeutic approaches $^{(1,8,9,11-13,22-24)}$.

Such lesions may present with multiple thin or slightly thickened septations (Figures 4 and 5), minimally thickened walls and regular contour. Enhancement may be observed after intravenous contrast injection, but the cystic content is not enhanced $^{(9,11-13,22,23,25)}$. Completely intrarenal hyperdense cysts larger than $3 \mathrm{~cm}$ with regular walls are also included in this category ${ }^{(9,13,22,25)}$.

These lesions may present with thick nodular calcifications (Figure 5) and irregular contours, increasing in volume with time, without indicating malignancy ${ }^{(12,13,22,23,25)}$. Israel et al. ${ }^{(12)}$ have demonstrated that all the lesions classified as category IIF presented calcifications, but also had their greatest concentrations. In some cases, because of the high number of such calcifications, the visualization of contrast enhancement may be difficult, so the use of images subtraction is suggested for differentiation between categories IIF and $\mathrm{III}^{(12)}$. Unfortunately, septations and wall thickening cannot be quantified to change a cyst category from II to $\mathrm{IIF}^{(22)}$.

Lesions classified as category IIF are primarily benign, but their complexity requires serial follow-up ("F" for fol-
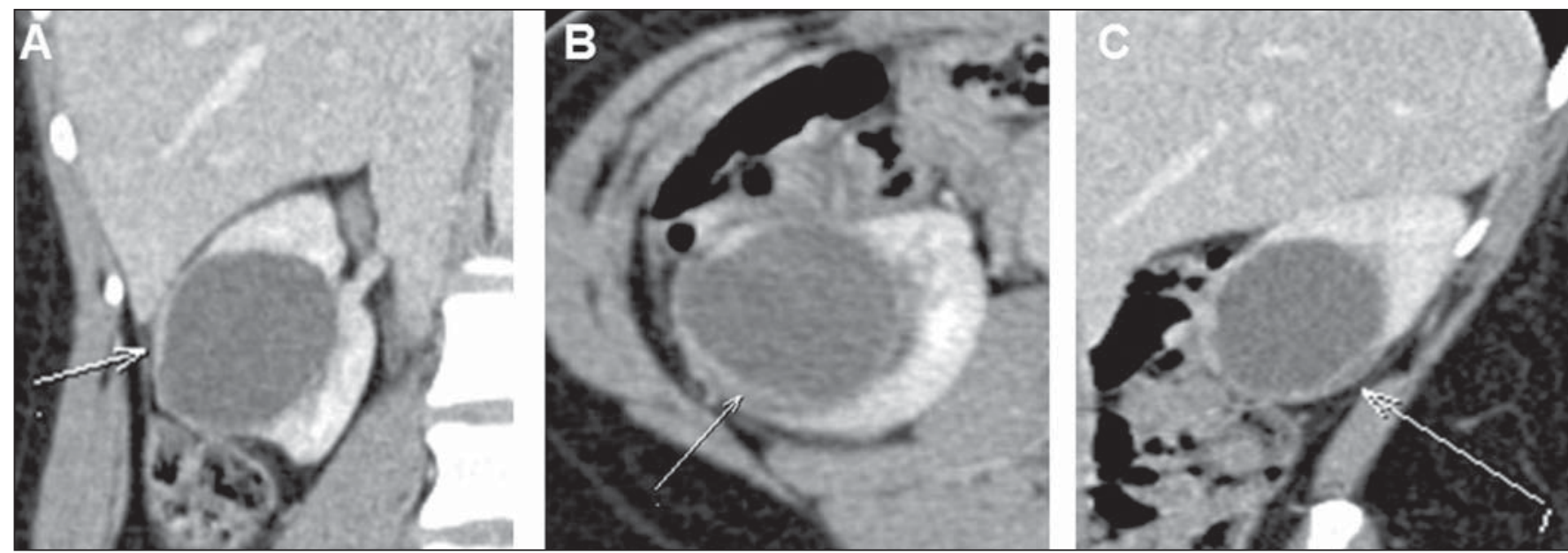

Figure 4. Bosniak category IIF. MDCT, coronal (A), axial (B) and sagittal (C) reconstructions demonstrating the presence of a right renal cystic lesion with parietal thickening (arrow on B) and a thin septum (arrow on C). Minimally complicated cyst requiring follow-up. 


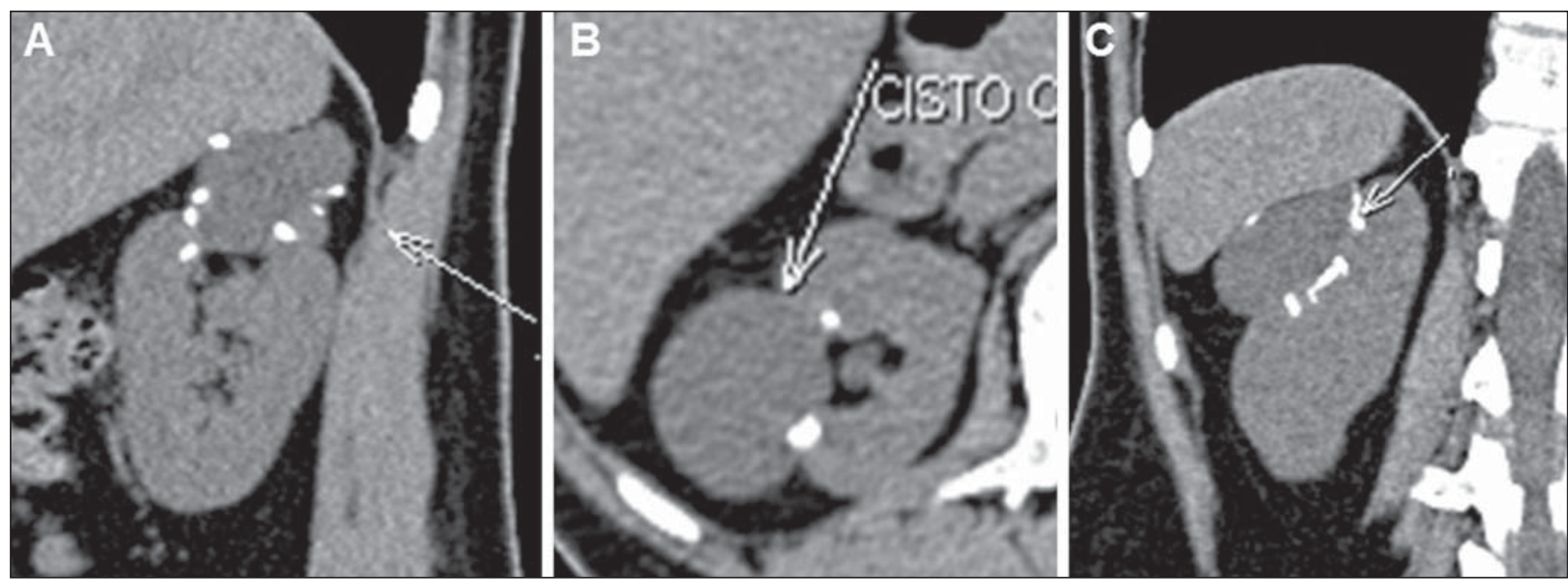

Figure 5. Bosniak category IIF. MDCT images, sagittal (A), axial (B) and coronal (C) reconstructions demonstrating the presence of a cystic lesion in the right kidney, with nodular, parietal calcifications. Minimally complicated cyst requiring follow-up.

low-up) to rule out (or not) the presence of malignancy ${ }^{(9,22-}$ 25). The appropriate follow-up time for determining IF a lesion is really benign is still to be established ${ }^{(9,22,23)}$ and varies in the literature. Some authors report the beginning of the follow-up 6 months after the initial evaluation, in association with an annual routine for a minimum of 5 years $^{(9,22)}$, while others support a follow-up at 3,6 and 12 months after the initial evaluation, in association with an annual routine ${ }^{(26)}$. Such a radiological follow-up has shown to be a safe strategy, avoiding surgical intervention in $95 \%$ of cases ${ }^{(9,10,23)}$.

Combined US and magnetic resonance imaging (MRI) should be considered in the follow-up of these patients, particularly for those under the age of 50, to reduce the exposition of such patients to radiation along the years ${ }^{(23)}$. A lesion category IIF which does not present increase or morphological alterations is probably benign, despite the fact that the lesion growth rate is not taken into consideration in the Bosniak classification, and the radiologist should evaluate principally the morphological alterations ${ }^{(9)}$.

\section{CATEGORY III}

Such lesions constitute really indeterminate renal findings, with a wide variety of aspects whose differentiation between malignant and benign cannot be reliably made by imaging methods. They present wall thickening and contrastenhanced, irregular and thick septations, either with or without calcifications $^{(9,13)}$ (Figures 6 and 7), and may be demonstrated as multilocular cysts (whose walls present with linear fibrosis), hemorrhagic or infected cysts, multilocular cystic nephromas (containing blastemas cells), or cystic renal cell carcinomas. Therefore, there is a significant risk for malignancy $^{(1,9,11,12,23)}$.

The introduction of the category IIF covering benign lesions that were previously classified as category III results in a higher percentage of malignant lesions, since probably benign lesions previously considered as category III are now classified as category IIF and duly undergo follow-up ${ }^{(9)}$. In case of doubt as regards classification, the lesion should be considered as category III, thus avoiding underdiagnosis of malignant lesions.
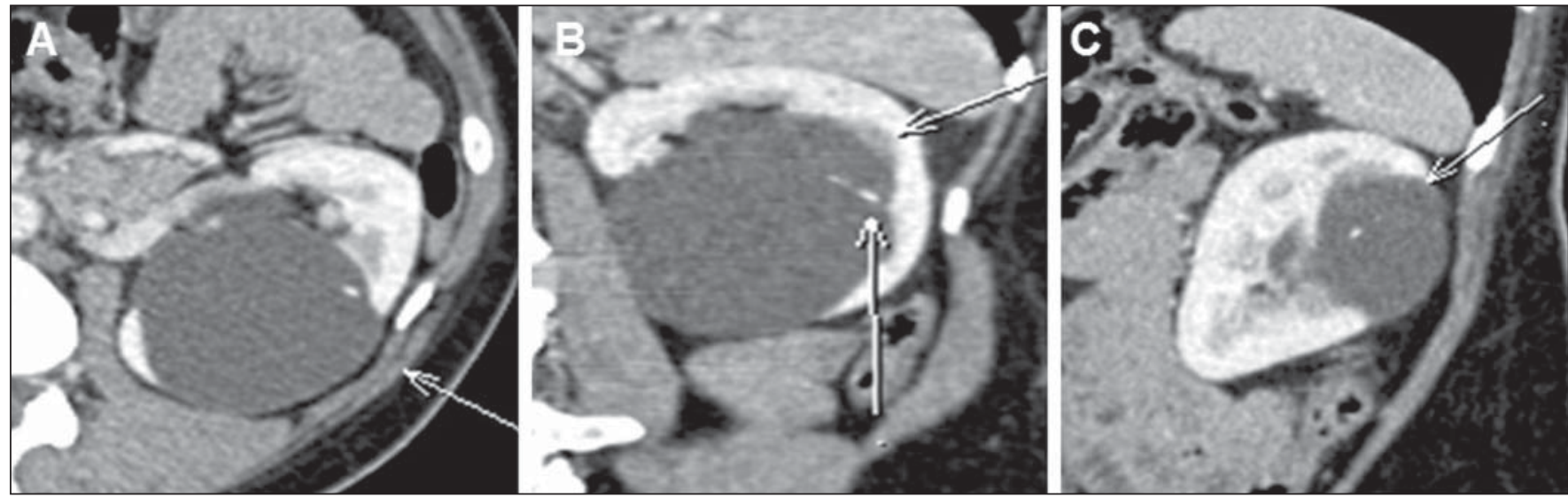

Figure 6. Bosniak category III. MDCT images axial (A), coronal (B) and sagittal (C) reconstructions identifying a cystic lesion in the left kidney, with thin septum and septal calcifications (arrows on B). Indeterminate cyst. 

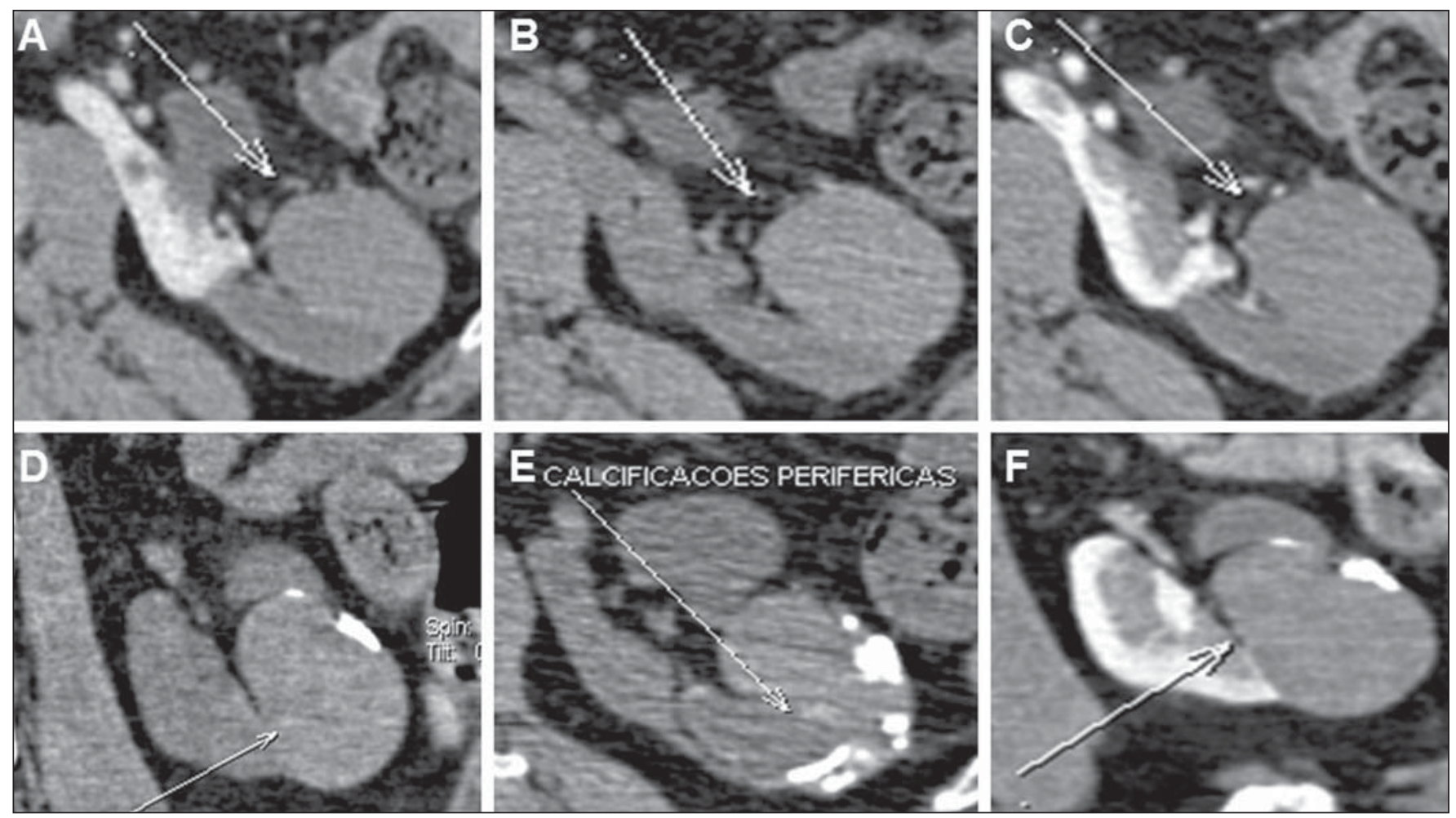

Figure 7. Bosniak category III. MDCT images, axial $(\mathbf{A}, \mathbf{B}, \mathbf{C}, \mathbf{E})$ and coronal $(\mathbf{D}, \mathbf{B})$ demonstrating a hyperattenuating mass in the left kidney, with peripheral Gross calcifications (arrow on E). Indeterminate cyst.

The prevalence of malignancy among resected lesions classified as category III ranges from $31 \%$ to $100 \%^{(9,24)}$, while other studies report a rate of malignancy between $40 \%$ and $60 \%{ }^{(10)}$. Such variations are due to the way the radiologist establishes the category, to the philosophy and preferential practice of the urologist who is treating the patient with indeterminate lesions ${ }^{(9)}$.

Nowadays it is possible to undertake a serial follow-up of such lesions with safety, provided soft parts components are not present. In case a septum or wall become thickened or irregular with no sign of growth of soft parts component, or simulation of soft parts component by the septum, the lesion should be considered as III (or IV), thus being surgically approached $^{(9,11,12,22,26)}$.

The option for an evaluation by means of percutaneous puncture is still seen with scepticism ${ }^{(26)}$. In the case of patients presenting a complex renal cyst with enhanced thickened and irregular walls, besides a history or findings (even remotely) suggestive of infection, or trauma resulting, for example, from a previous puncture, needle biopsy will be indicated $^{(1)}$.

\section{CATEGORY IV}

Lesions in this category are cystic neoplasms which may present imaging findings similar to those of category III (wall thickening or gross and nodular septal thickening), but contrast-enhanced solid components are still observed adjacent to the lesion wall or septa ${ }^{(1,9)}$ (Figures 8 and 9). Until proven otherwise, such lesions are considered renal cell cancer with eminently surgical indication, since they are malignant in $95-100 \%$ of cases $^{(9,10)}$.

Occasionally, the differentiation between lesions in categories III and IV may be difficult, but it is not essential since both categories require surgery, despite the difference in the operative approach $^{(10,13)}$.

\section{CONCLUSION}

The Bosniak classification is a practical and accurate method to evaluate renal cystic lesions, also limiting the number of patients wrongly diagnosed with complex lesions and submitted to unnecessary surgeries. Because of the high prevalence of these lesions, radiologists and urologists must be familiar with their existence, imaging findings and possible associated complications in order to identify and classify them in their daily practice, allowing the establishment of the therapeutic approach.

In spite of the fact that the Bosniak classification was based on CT findings, the same approach can be established on the basis of MRI that is capable of identifying characteristics which otherwise are not identifiable at CT. However, such evaluations by different imaging methods may not be clearly correlated. MRI does not demonstrate calcifications, but can demonstrate some parietal or septal thickenings which cannot be seen at CT, resulting in an upgrade in the classification for malignancy ${ }^{(1,13)}$.

US is another imaging method that is widely utilized for initial assessment of renal lesions, since it is a low cost and easily accessible method that does not require ionizing 

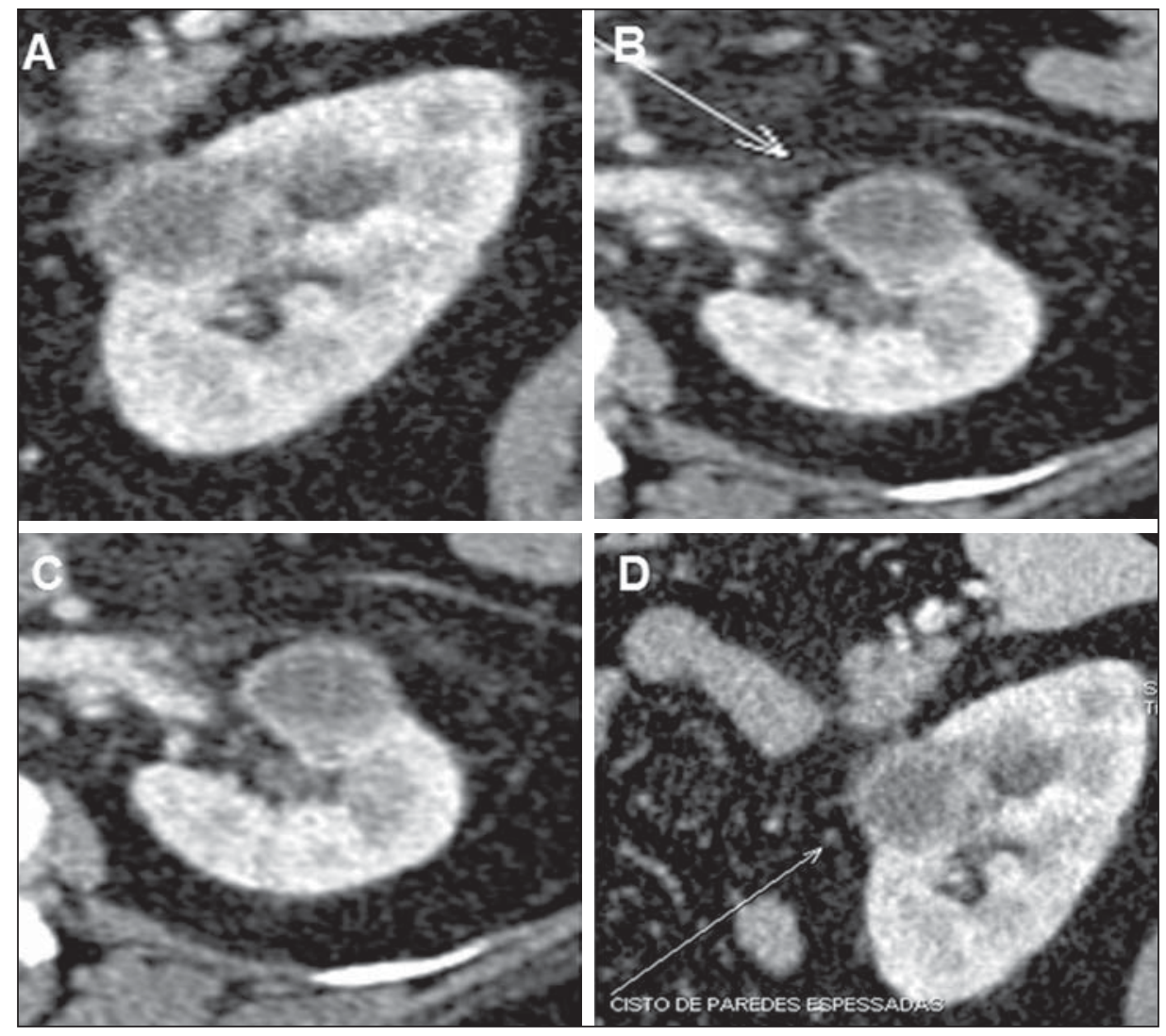

Figure 8. Bosniak category IV. MDCT images, sagittal $(\mathbf{A}, \mathbf{D})$ and axial $(\mathbf{B}, \mathbf{C})$ reconstructions demonstrating a cystic lesion with gross and nodula parietal thickening.

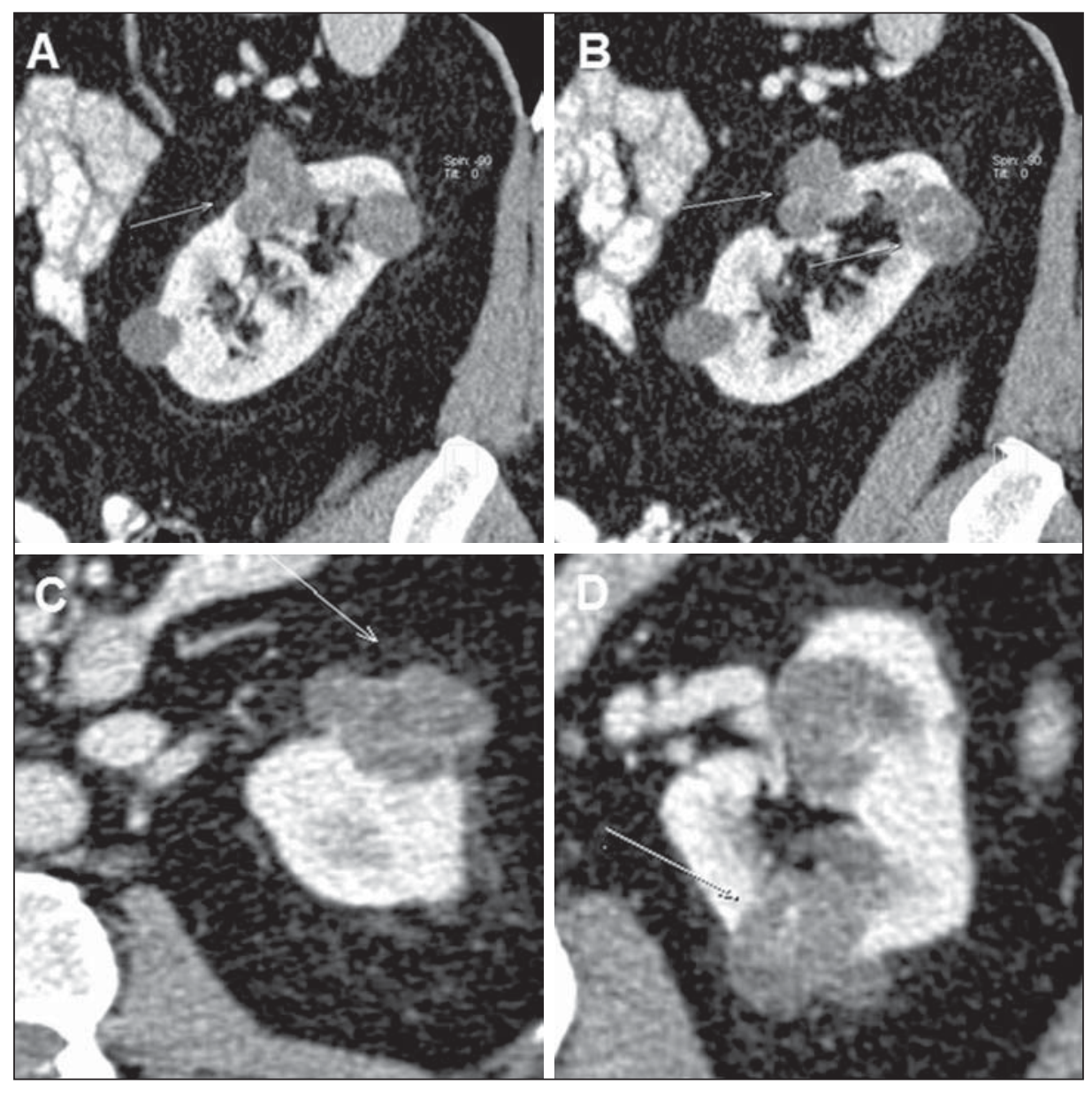

Figure 9. Bosniak category IV. MDCT images, sagittal $(\mathbf{A}, \mathbf{B})$ and axial $(\mathbf{C}, \mathbf{D})$ reconstructions demonstrating lobulated cystic lesions with contrastenhanced, thickened septa. 
radiation and use of intravenous contrast agents ${ }^{(27)}$. Its main characteristic is the identification of focal parenchymal lesions, classifying them into: simple cysts, solid or indeterminate (cystic but not simple) mass ${ }^{(10,27)}$. The inaccuracy of this method for the Bosniak classification is principally due to the absence of contrast material, considering that the enhancement of the solid components of a cyst is a crucial factor $^{(25)}$. However, studies report the utilization of contrastenhanced harmonic US with a diagnostic capability similar to that of MDCT, also suggesting its utilization for those patients requiring follow-up with lower degree of exposure to radiation ${ }^{(25)}$.

\section{REFERENCES}

1. Israel GM, Bosniak MA. How I do it: evaluating renal masses. Radiology. 2005;236:441-50.

2. D’Ippolito G, Torres LR, Ribeiro ACR, et al. Alcoolização percutânea de cistos renais: revisão da literatura e apresentação de resultados. Radiol Bras. 2009;42:225-30.

3. Lee J, Darcy M. Renal cysts and urinomas. Semin Intervent Radiol. 2011;28:380-91.

4. Bosniak MA. The current radiological approach to renal cysts. Radiology. 1986;158:1-10.

5. Chang CC, Kuo JY, Chan WL, et al. Prevalence and clinical characteristics of simple renal cyst. J Chin Med Assoc. 2007;70:48691.

6. Terada N, Arai Y, Kinukawa N, et al. Risk factors for renal cysts. BJU Int. 2004;93:1300-2.

7. Bosniak MA. Dif?culties in classifying cystic lesions of the kidney. Urol Radiol. 1991;13: 91-3.

8. Bosniak MA. Diagnosis and management of patients with complicated cystic lesions of the kidney. AJR Am J Roentgenol. 1997;169: 819-21.

9. Silverman SG, Israel GM, Herts BR, et al. Management of the incidental renal mass. Radiology. 2008;249:16-31.

10. Sociedade Brasileira de Urologia. Câncer renal: diagnóstico e estadiamento. Projeto Diretrizes. Associação Médica Brasileira e Conselho Federal de Medicina; 2006. [acessado em 20 de fevereiro de 2013]. Disponível em: www.projetodiretrizes.org.br/6_volume/09cancerrenaldiagnestad.pdf.

11. Bertolotto M, Zappetti R, Cavallaro M, et al. Characterization of atypical cystic renal masses with MDCT: comparison of 5-mm axial images and thin multiplanar reconstructed images. AJR Am J Roentgenol. 2010;195:693-700.

12. Israel GM, Bosniak MA. Calcification in cystic renal masses: is it important in diagnosis? Radiology. 2003;226:47-52.

13. Israel GM, Hindman N, Bosniak MA. Evaluation of cystic renal masses: comparison of CT and MR imaging by using the Bosniak classification system. Radiology. 2004;231:365-71.

14. O'Connor SD, Pickhardt PJ, Kim DH, et al. Incidental finding of renal masses at unenhanced CT: prevalence and analysis of features for guiding management. AJR Am J Roentgenol. 2011;197:13945.

15. Israel GM, Bosniak MA. An update of the Bosniak renal cyst classification system. Urology. 2005;66:484-8.

16. Bosniak MA. The small (less than or equal to $3.0 \mathrm{~cm}$ ) renal parenchymal tumor: detection, diagnosis, and controversies. Radiology. 1991;179:307-17.

17. Hartman DS, Weatherby E 3rd, Laskin WB, et al. Cystic renal cell carcinoma: CT findings simulating a benign hyperdense cyst. AJR Am J Roentgenol. 1992;159:1235-7.

18. Chung EP, Herts BR, Linnell G, et al. Analysis of changes in attenuation of proven renal cysts on different scanning phases of triphasic MDCT. AJR Am J Roentgenol. 2004;182:405-10.

19. Siegel CL, McFarland EG, Brink JA, et al. CT of cystic renal masses: analysis of diagnostic performance and interobserver variation. AJR Am J Roentgenol. 1997;169:813-8.

20. Spaliviero M, Herts BR, Magi-Galluzzi C, et al. Laparoscopic partial nephrectomy for cystic masses. J Urol. 2005;174:614-9.

21. Israel GM, Bosniak MA. Follow-up CT of moderately complex cystic lesions of the kidney (Bosniak category IIF). AJR Am J Roentgenol. 2003; 181:627-33.

22. Bosniak MA. Problems in the radiologic diagnosis of renal parenchymal tumors. Urol Clin North Am. 1993;20:217-30.

23. Whelan TF. Guidelines on the management of renal cyst disease. Can Urol Assoc J .2010;4:98-9.

24. Smith AD, Remer EM, Cox KL, et al. Bosniak category IIF and III cystic renal lesions: outcomes and associations. Radiology. 2012;262: $152-60$.

25. Ascenti G, Mazziotti S, Zimbaro G, et al. Complex cystic renal masses: characterization with contrast-enhanced US. Radiology. 2007;243: 158-65.

26. Eknoyan G. A clinical view of simple and complex renal cysts. J Am Soc Nephrol. 2009;20:1874-6.

27. Weber TM. Sonography of benign renal cystic disease. Ultrasound Clinics. 2006; 1:15-24. 